\title{
Apelin-13 Regulates Angiotensin II-Induced Cx43 Downregulation and Autophagy via the AMPK/mTOR Signaling Pathway in HL-1 Cells
}

\author{
Yifan CHEN ${ }^{1}$, Xi QIAO' ${ }^{2}$, Lijun ZHANG ${ }^{2}$, Xuewen LI' ${ }^{1}$, Qinghua LIU ${ }^{2}$ \\ ${ }^{1}$ Shanxi Bethune Hospital Affiliated to Shanxi Medical University, Tiaiyuan, China, ${ }^{2}$ Department of \\ Pathophysiology, Shanxi Medical University, Taiyuan, China
}

Received April 18, 2020

Accepted August 1, 2020

Epub Ahead of Print September 9, 2020

\begin{abstract}
Summary
Atrial fibrillation is associated with atrial remodeling, in which connexin 43 (Cx43) and cell hypertrophy play important roles. In this study, apelin-13, an aliphatic peptide, was used to explore the protective effects of the adenosine monophosphate-activated protein kinase (AMPK)/mTOR signaling pathway on Cx43 expression and autophagy, using murine atrial $\mathrm{HL}-1$ cells. The expression of Cx43, AMPK, B-type natriuretic peptide (BNP) and pathway-related proteins was detected by Western blot analysis. Cellular fluorescence imaging was used to visualize Cx43 distribution and the cytoskeleton. Our results showed that the Cx43 expression was significantly decreased in $\mathrm{HL}-1$ cells treated with angiotensin II but increased in cells additionally treated with apelin-13. Meanwhile, apelin-13 decreased BNP expression and increased AMPK expression. However, the expression of Cx43 and LC3 increased by apelin-13 was inhibited by treatment with compound $\mathrm{C}$, an AMPK inhibitor. In addition, rapamycin, an mTOR inhibitor, promoted the development of autophagy, further inhibited the protective effect on Cx43 expression and increased cell hypertrophy. Thus, apelin-13 enhances Cx43 expression and autophagy via the AMPK/mTOR signaling pathway, and serving as a potential therapeutic target for atrial fibrillation.
\end{abstract}

\section{Key words}

Atrial fibrillation - Cx43 - Cell hypertrophy - AMPK/mTOR • Autophagy

\section{Corresponding authors}

X. Li, Shanxi Bethune Hospital Affiliated to Shanxi Medical University, 99 Longcheng Street, XiaoDian District, Taiyuan
030024, China. E-mail: xuewenli1010@126.com and Q. Liu, Department of Pathophysiology, Shanxi Medical University, 56 Xinjian South Road, Taiyuan 030001, China. E-mail: liuqh_w@sxmu.edu.cn

\section{Introduction}

Intercalated discs (IDs) are a specific structure in the heart muscle that play a crucial role in signal transduction. Gap junctions in the IDs allow many small molecules to pass through the cell membrane (Leybaert et al. 2017). Connexin 43 (Cx43), the major connexin in gap junctions, is highly expressed in cardiac muscle (Xiao et al. 2016). Gap junctions consist thousands intercellular channels composed of $\mathrm{Cx} 43$ and these channels are responsible for electrical and molecular signal propagation between cardiomyocytes. Therefore, the changes in topology of $\mathrm{Cx} 43$ or in the number of $\mathrm{Cx} 43$ channels which is largely determined by expression affect electrical properties of the myocardial tissue that promote arrhythmias, including $\mathrm{AF}$.

Atrial fibrillation (AF) is a highly prevalent cardiac arrhythmia in clinical practice (Liu et al. 2013) with high morbidity and mortality rates and therefore associated with major health care costs (Chugh et al. 2014). Therefore, treatments that preserve $\mathrm{Cx} 43$ remodeling may represent a new strategy for AF management.

In 1998, Tatemoto et al. (1998) discovered a protein hormone from bovine stomach, which was later shown to have numerous biological functions, including a direct or indirect effect on cardiovascular physiology 
(Lesui 2015). Numerous studies have indicated that apelin-13 exerts a cardioprotective effect in cardiac pathologies, including cardiac hypertrophy, fibroblast activation, vasoconstriction and myocardial infarction, but the relationship between apelin-13 and hypertrophy is not clear. Furthermore, apelin-13 was previously demonstrated to upregulate $\mathrm{Cx} 43$ remodeling under highglucose conditions ( $\mathrm{Li}$ et al. 2018). Thus, we assumed that apelin-13 plays a role in the regulation of atrial Cx43 expression and hypertrophy.

Autophagy is a catabolic process in which intracellular metabolites are engulfed by autophagosomes to promote cell renewal, recycling and maintain cellular homeostasis (Levine et al. 2004). In the heart, considerable evidence has shown that autophagy is involved in a series of physiological and pathological processes (Rockel et al. 2017). Even within the same cell, both up- and downregulation of autophagy can cause damage and ultimately lead to cell death. Another study found that decreased $\mathrm{Cx} 43$ expression had an inhibitory effect on cell survival, suggesting that $\mathrm{Cx} 43$ expression can alter cell-cell communication and contribute to apoptosis (Li et al. 2009). Several studies have indicated that the adenosine monophosphate-activated protein kinase (AMPK)/mTOR pathway, which is involved in numerous cellular processes, has a crucial effect on autophagy, affecting cell survival and death (Tang et al. 2016). Some publications reported that the AMPK/mTOR pathway participates in regulating cardiac Cx43 remodeling and autophagic flux, but few studies have evaluated the role of the AMPK/mTOR pathway in angiotensin II (AngII)-induced Cx43 dysfunction and hypertrophy and the protective effect conferred by apelin13 on these mechanisms.

Here, we explored the potential protective effects of apelin-13 on AngII-induced Cx43 downregulation and cell hypertrophy via the AMPK/mTOR pathway in HL-1 cells. Our findings demonstrated that upregulation of autophagy inhibits cardiac Cx43 expression and increases cell hypertrophy.

\section{Materials and Methods}

\section{Cell culture and experimental protocols}

Murine HL-1 cells were cultured in high-glucose Dulbecco's modified Eagle medium (DMEM) containing $10 \%$ fetal bovine serum (FBS, Biological Industries, USA) and $1 \%$ penicillin/streptomycin solution in a humidified incubator containing $5 \% \mathrm{CO}_{2}$ and $95 \%$ air at $37^{\circ} \mathrm{C}$. HL-1 cells were allowed to grow to approximately $85 \%$ confluence and were then incubated for an additional $24 \mathrm{~h}$ under starvation conditions (without FBS). The cells were then treated with different concentrations of AngII $(0.1,1$ and $10 \mu \mathrm{M}$, MedChemExpress, NJ, USA) alone or in combination with apelin-13 (10, 100 and $1000 \mathrm{nM}$, Santa Cruz Biotechnology, USA, for $48 \mathrm{~h}$. Simultaneously, cells were treated with $10 \mu \mathrm{M}$ compound $\mathrm{C}$, dissolved in PBS, MedChemExpress), or the autophagy agonist rapamycin (MedChemExpress), dissolved in dimethyl sulfoxide (DMSO) and then diluted in high-glucose DMEM to a final concentration of $10 \mathrm{nM}$. The concentration of DMSO in cell medium was $1 \%$, which had no influence on cell viability. All drugs were freshly dissolved before each experiment.

\section{Measurement of cell size}

Upon reaching approximately $60 \%$ confluence, HL-1 cells on slides were washed twice with PBS at $37^{\circ} \mathrm{C}$. The cultured cells were then fixed with $4 \%$ formaldehyde for $10 \mathrm{~min}$ at room temperature. After three washings, the cells were treated with $0.5 \%$ Triton X-100 for $5 \mathrm{~min}$ at room temperature. After washing three more times, the cells were incubated with $200 \mu \mathrm{l}$ FITCphalloidin diluted in $1 \%$ bicinchoninic acid (BCA, Solarbio, Beijing, China) for $30 \mathrm{~min}$ at $37^{\circ} \mathrm{C}$. Finally, the cells were lightly washed and incubated with DAPI for approximately $30 \mathrm{~s}$. A fluorescence microscope was used to visualize and photograph the HL-1 cells. Image J software was used to calculate the HL-1 cell surface area in each group.

\section{Immunofluorescence staining}

After treatment, the cells in each group were washed with $1 \times$ PBS three times and then fixed with $4 \%$ formaldehyde for $15 \mathrm{~min}$ at room temperature. The cells were washed in PBS, blocked with $5 \%$ goat serum for $1 \mathrm{~h}$ and incubated with a $\mathrm{Cx} 43$ antibody (1:100 dilution, ABclonal, Wuhan, China) overnight at $4{ }^{\circ} \mathrm{C}$ temperature. After three washes with PBS the following day, the cells were incubated with a secondary fluorescent antibody diluted 1:500 for $1 \mathrm{~h}$. The cells were then washed again, and DAPI was incubated with the cell nuclei for approximately $15 \mathrm{~min}$. Finally, the cells were visualized under a fluorescence microscope.

\section{Western blot analysis}

After harvesting HL-1 cells, proteins were 
isolated by incubating in RIPA lysis buffer for approximately $30 \mathrm{~min}$ on ice. The resulting protein lysate was centrifuged at $12000 \times \mathrm{g}$ for $10 \mathrm{~min}$. The BCA assay was used to measure the protein concentrations in each group, and $30-60 \mu \mathrm{g}$ protein were resolved by $10 \%$ sodium dodecyl sulfate polyacrylamide gel electrophoresis. The separated proteins were then transferred to polyvinylidene difluoride membranes. The membranes were blocked using $5 \%$ non-fat dry milk or $5 \%$ bovine serum albumin for $2 \mathrm{~h}$ at room temperature and incubated overnight at $4{ }^{\circ} \mathrm{C}$ with primary antibodies against $\mathrm{Cx} 43$ (1:1000, Cell Signaling Technology), LC3B (1:1000, Cell Signaling Technology), p-AMPK, AMPK (1:1000, Sangon Biotech, Shanghai, China), mTOR (1:1000, Sigma-Aldrich) and B-type natriuretic peptide (BNP) (1:1000, Wanleibio, Shengyang, China). GAPDH was used as a loading control (1:3000, Sigma-Aldrich) in each case. The following day, the membranes were washed with TBST for $30 \mathrm{~min}$ and then incubated with HRP secondary antibodies for $2 \mathrm{~h}$ at room temperature. After three 10-min washes with TBST, the membranes were treated with an enhanced chemiluminescence kit and exposed to X-ray films. Image $\mathrm{J}$ software 6.0 was used to quantify all protein bands.

\section{Statistical analysis}

The data are expressed as means \pm standard error (SEM). Comparisons among groups were evaluated using one-way analysis of variance (ANOVA) followed by the Student-Newman-Keuls test. Prism GraphPad 6.0 software (GraphPad Software Inc., San Diego, CA, USA) was used for the data analysis. $p<0.05$ was considered to represent statistical significance.

\section{Results}

Apelin-13 restored the Cx43 downregulation induced by AngII in HL-1 cells

Cells were separately treated with AngII (0.1, 1 and $10 \mu \mathrm{M})$ (Fig. 1A) and apelin-13 (10, 100 and $1000 \mathrm{nM}$ ) (Fig. 1B) for $48 \mathrm{~h}$. Treatment with $10 \mu \mathrm{M}$ AngII alone resulted in significant downregulation of Cx43 expression. Whereas treatment with apelin-13 alone at each concentration resulted in no change in $\mathrm{Cx} 43$ expression, when co-treated with $10 \mu \mathrm{M}$ AngII for $48 \mathrm{~h}$, apelin-13 reversed the decrease in $\mathrm{Cx} 43$ induced by AngII. This protective effect of apelin-13 occurred in a concentration-dependent manner, peaking at $100 \mathrm{nM}$ (Fig. 1C).

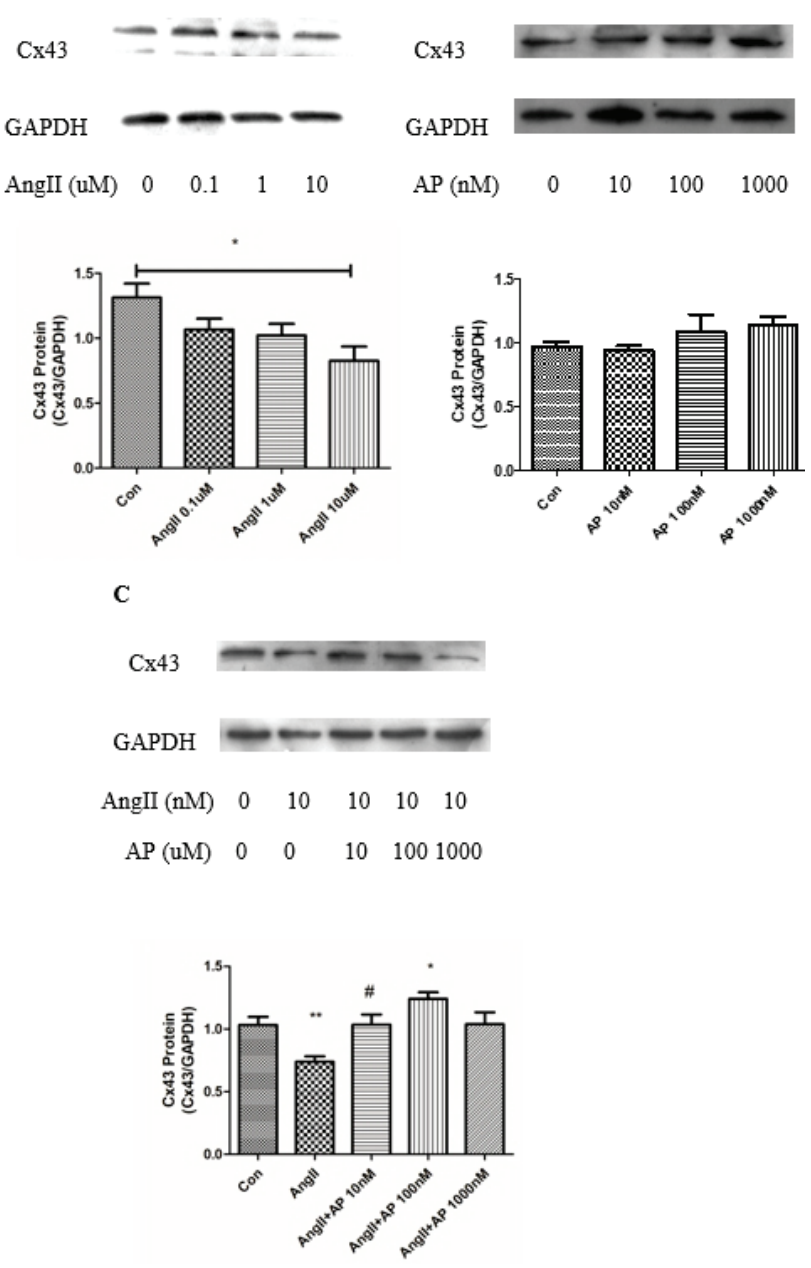

Fig. 1. Effect of AngII and apelin-13 on Cx43 expression in HL-1 cells. AngII $(10 \mu \mathrm{M}, 48 \mathrm{~h})$ downregulated $\mathrm{Cx} 43$ expression (A), whereas apelin-13 (100 nM, $48 \mathrm{~h})$ had no significant effect on Cx43 expression at the various concentrations used (B). Subsequent incubation with both AngII and apelin-13 restored the Cx43 downregulation induced by AngII (C). Control: normal incubation; AngII: angiotensin II; AP: apelin-13. $\mathrm{n}=5$; ** $p<0.01$, vs. control; $* p<0.05$, vs. AngII; ${ }^{*} p<0.05$, vs. AngII.

Compound $C$ and rapamycin inhibited AMPK expression and abolished the protective effect of apelin-13

As we found that apelin-13 had a stimulatory effect on AMPK expression, AMPK expression was measured in cells treated with compound C, an AMPK inhibitor, as a negative control. Rapamycin, a common activator of autophagy and inhibitor of mTOR activity, was also used to investigate the correlation between AMPK expression and autophagy. Under treatment with AngII and apelin-13, cells were additionally treated with compound $\mathrm{C}(10 \mu \mathrm{M})$ and rapamycin $(10 \mathrm{nM})$ for $48 \mathrm{~h}$, and the expression of AMPK was assessed by Western blot analysis. The results showed that both compound $\mathrm{C}$ and rapamycin significantly decreased AMPK expression, which was prevented by apelin-13 (Fig. 2A) 
A

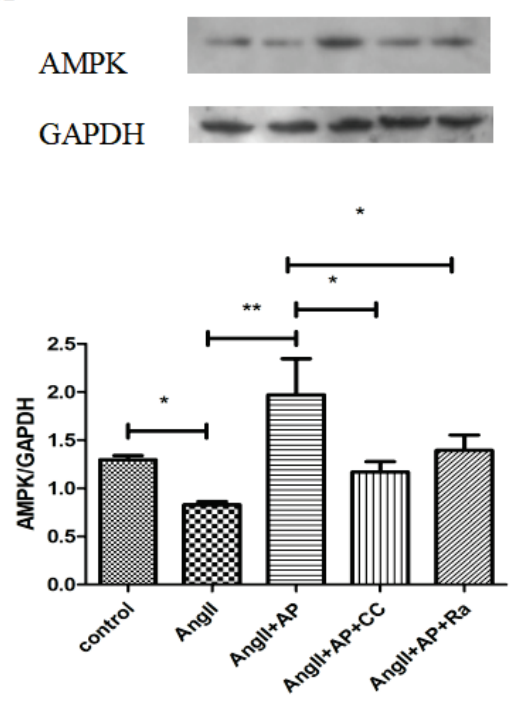

C

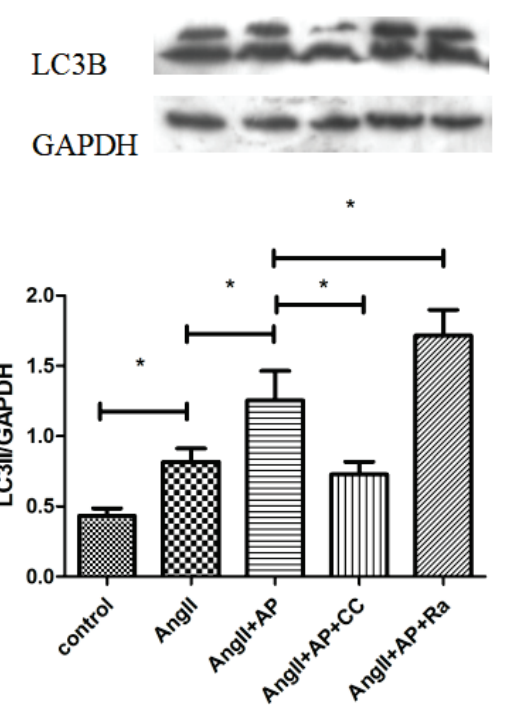

B

mTOR

GAPDH

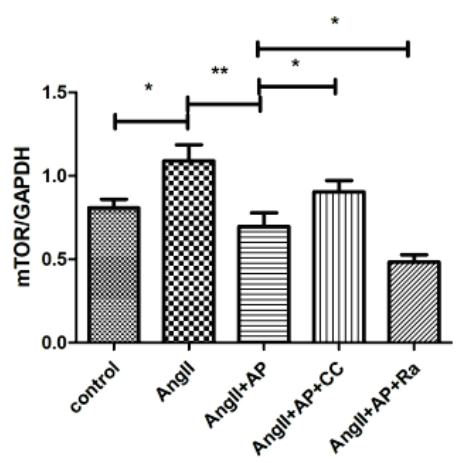

Fig. 2. The $A M P K / m T O R$ signaling pathway was involved in autophagy of $\mathrm{HL}-1$ cells. Compared with the control group, the expression of AMPK decreased (A) but mTOR and LC3II (C) increased (B) with AngII alone, whereas addition of AP reversed those change. Under treatment with AngII+AP, adding CC or Ra downregulated AMPK expression. mTOR expression increased with the addition of CC but decreased with the addition of Ra while LC3II expression decreased with the addition of CC but increased with the addition of Ra. $\mathrm{n}=6 ; * p<0.05 ; * * p<0.01$.
Apelin-13 promoted autophagy via the AMPK/mTOR signaling pathway

To assess the effect of apelin-13 on autophagic activation in HL-1 cells and the role of the AMPK/mTOR signaling pathway in this effect, rapamycin $(10 \mathrm{nM})$ and compound $\mathrm{C}(10 \mu \mathrm{M})$ were used to disrupt AMPK/ mTOR signaling, and the expression of mTOR and the autophagic marker LC3 was examined (Figs. 2B, C). Compared with AngII treatment alone, the expression of mTOR was decreased and that of LC3 increased in cells treated with both AngII and apelin-13. Remarkably, activation of autophagy was further promoted by rapamycin, as indicated by decreased mTOR expression and increased LC3II expression. However, compound C prevented apelin-13-induced autophagic activation, according to increased mTOR expression and decreased LC3II expression.
Apelin-13 reversed AngII-induced downregulation of CX43 expression and distribution via the AMPK/mTOR signaling pathway

Apelin-13 prevented the downregulation of Cx43 expression induced by AngII (Fig. 3A). Compound $\mathrm{C}$ and rapamycin were used to determine whether this effect is mediated by the AMPK/mTOR signaling pathway. Cell immunofluorescence was also used to visualize the distribution and expression of $\mathrm{Cx} 43$ under the same treatment (Fig. 3B, C). Compared with AngII and apelin-13 treatment, adding additional compound $\mathrm{C}$ $(10 \mu \mathrm{M})$ or rapamycin $(10 \mathrm{nM})$ decreased $\mathrm{Cx} 43$ expression and distribution, and rapamycin had a greater effect than compound $\mathrm{C}$. These data further supported the correlation between $\mathrm{Cx} 43$ expression and AMPK/mTOR signaling pathway. 
A.

Cx43

GAPDH

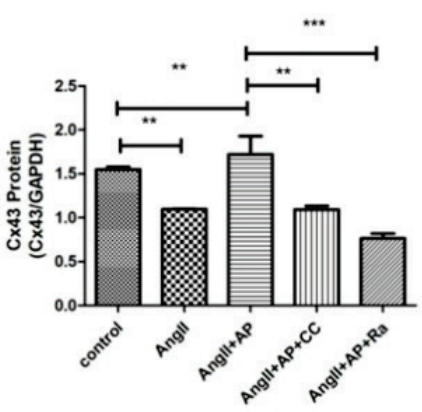

C. $\mathrm{Cx} 43$
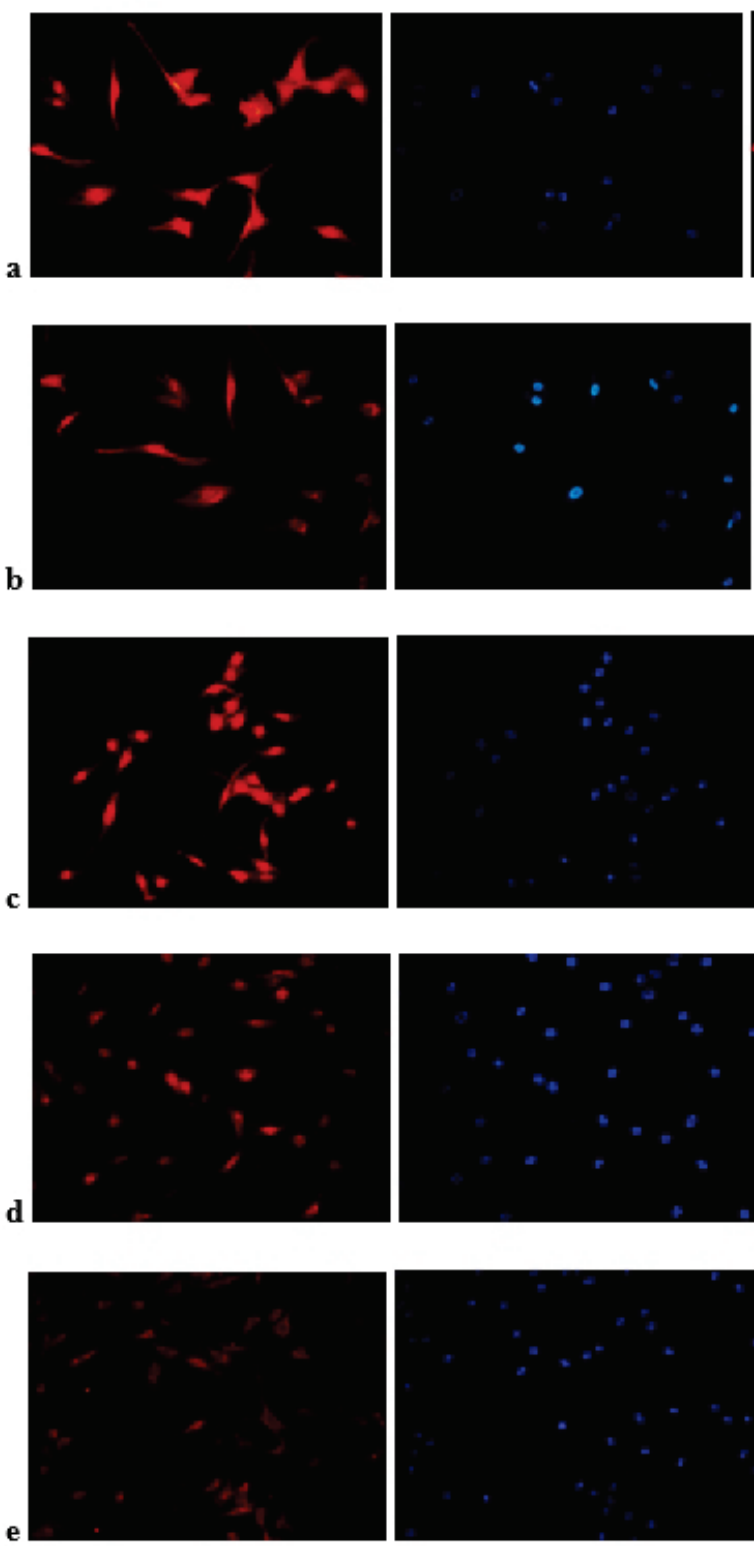
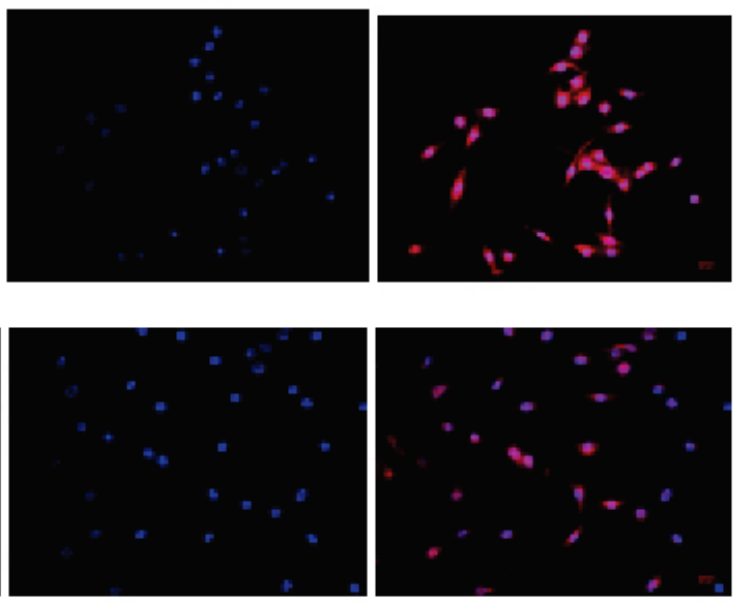

B.

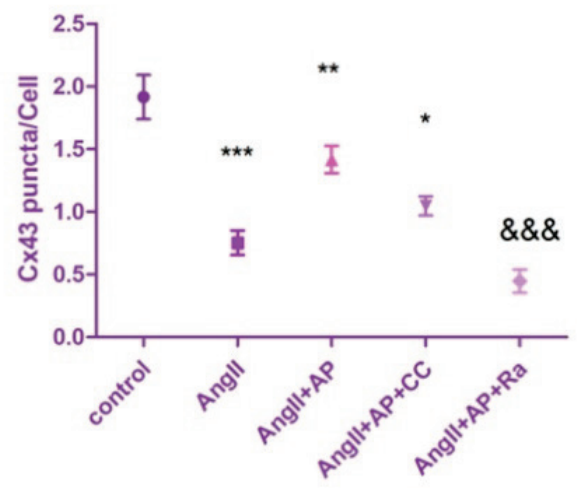

Merge
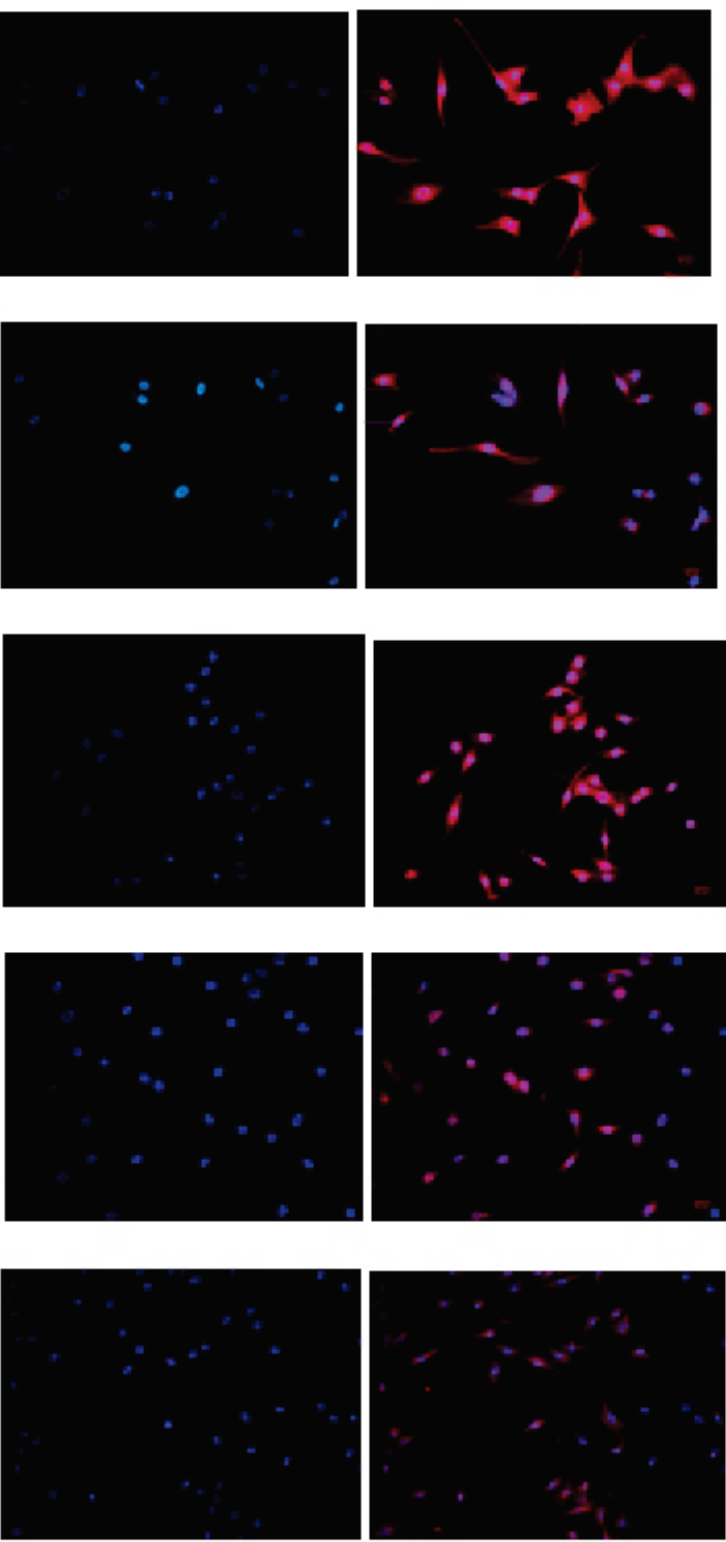

Fig. 3. The effects of compound $C$ and rapamycin on Cx43 expression and distribution. Cx43 expression and distribution in $\mathrm{HL}-1$ cells was determined by cell immunofluorescence and Western blot analysis. (A) Compared with the control group, Cx43 expression and distribution in the AngII group was decreased, whereas addition of apelin-13 restored Cx43 expression. Under the treatment of AngII and apelin-13, adding CC or Ra downregulated the expression and distribution of $\mathrm{C} \times 43$. (B, C) $\mathrm{n}=6$; $* p<0.05$ vs. AngII+AP; $* * p<0.01$ vs. AngII; $\quad * * * p<0.001$ vs. Control; \&\&\& $p<0.001$ vs. AngII+AP. 
Rapamycin reversed the downregulation of $B N P$ and cell hypertrophy induced by apelin-13

The protein level of BNP was measured to assess HL-1 cell hypertrophy, (Fig. 4A) and cell immunofluo-rescence using FITC-phalloidin was performed to assess cytoskeletal structure (Fig. 4B, C).
Western blot analysis showed that apelin-13 decreased the expression of BNP, which was highly increased by rapamycin. Cellular staining with FITC-phalloidin revealed that the effect of apelin-13 on cell size was reversed by rapamycin. However, compound $\mathrm{C}$ had no apparent effect.
A. BNP

GAPDH

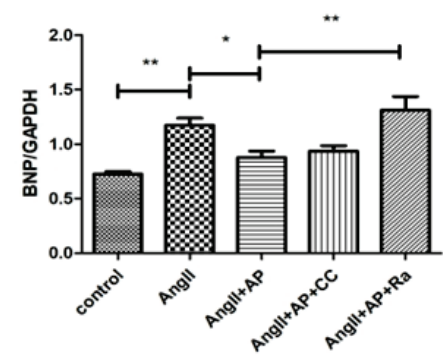

C.

Cx43
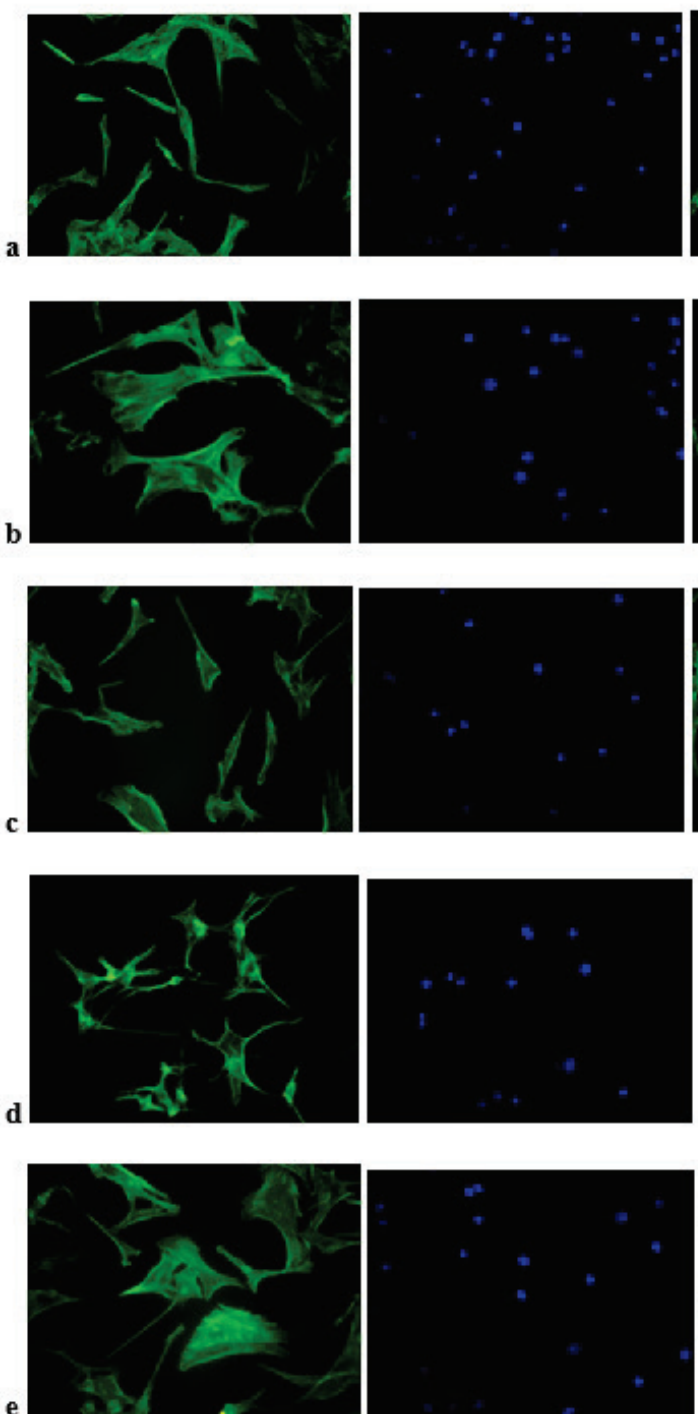

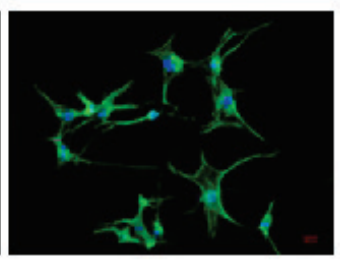

B.

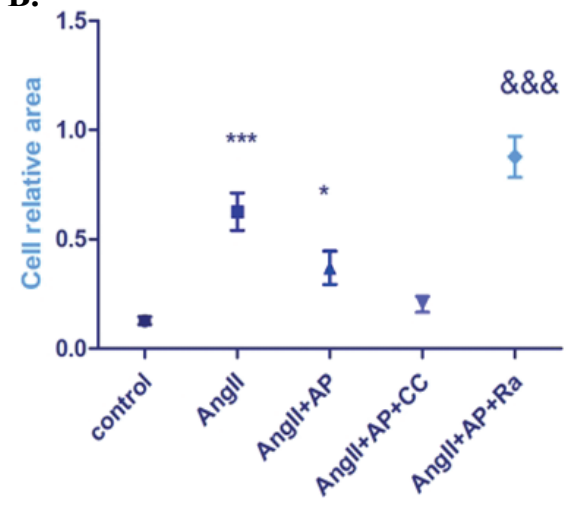

Merge
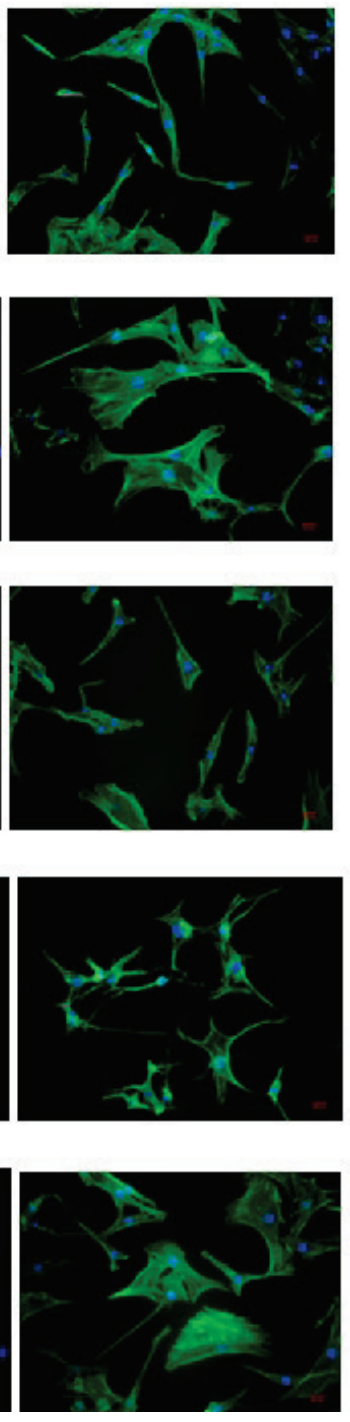

Fig. 4. The effects of compound $C$ and rapamycin on BNP expression and $\mathrm{HL}-1$ cell size. Compared with the control group, the expression of BNP (A) and cell size $(\mathbf{B}, \mathbf{C})$ were increased in AngII group but significantly decreased in the AngII+AP group. Addition of $\mathrm{Ra}$ in the AngII+AP group reversed the downregulation of BNP expression and cell size, whereas CC did not significantly affect either BNP expression or cell size. $n=6$; a: control; b: AngII; c: AngII+AP; d: AngII+AP+CC; e: AngII+AP+RA; $* * * p<0.001$ vs. control; $* p<0.05$ vs. AngII; ${ }^{\& \& \&} p<0.001$ vs. AngII+AP. 


\section{Discussion}

Our study investigated the effects of apelin-13 on Cx43 expression and autophagy induced by AngII and on the AMPK/mTOR signaling pathway, as the potential mechanism. The results demonstrated the following: 1) apelin-13 accentuated the AngII-induced decrease in Cx43 expression in HL-1 cells; 2) apelin-13 reversed the AngII-induced decrease in AMPK expression in HL-1 cells; 3) AMPK/mTOR signaling mediated the protective effect of apelin-13 on Cx43 expression and distribution, and induction of autophagy reversed this effect; 4) $A M P K / m T O R$ signaling mediated the increase in autophagy induced by apelin-13; and 5) apelin-13 prevented the AngII effects on cell hypertrophy, according to BNP expression, and cell size, but induction of autophagy reversed these effects.

AngII participates in a variety of cardiovascular pathophysiological processes that can lead to cardiac arrhythmia, including fibrosis, inflammation, vasoconstriction, cardiac hypertrophy, oxidative stress, ion channel dysfunction and ID protein remodeling (Valls-Lacalle et al. 2019). AF is the most common tachyarrhythmia in clinical practice, causing increased mortality and morbidity, and it has a major economic burden (Heijman et al. 2015). Activation of the reninangiotensin system increased the level of AngII in heart tissue and promoted the development of AF (Tsai et al. 2008). Researchers have developed a model of AF triggered by AngII in mice, and multiple signaling pathways that stimulate atrial fibrosis, inflammation and oxidative stress, leading to AF inducibility, have been discovered ( $\mathrm{Li}$ et al. 2018). Some studies have used AngII to generate a model of cardiac remodeling in HL-1 cells (Miteva et al. 2016). Accordingly, we chose to also use these murine atrial myocytes, which have differentiation potential and maintain spontaneous depolarization, as a model of cell remodeling induced by AngII.

Cx43 is an important component of Intercalated disc protein and has been investigated extensively in the cardiac system. Recent studies discovered that $\mathrm{Cx} 43$ abnormal remodeling promoted the development of AF in guinea pig hearts, and the same was found in AF patients (Shinohara et al. 2017, Nagibin et al. 2016). This indicates that abnormalities in connexin expression and distribution, as factors involved in atrial remodeling, play an important role in $\mathrm{AF}$ and may be a potential therapeutic target for AF-induced atrial remodeling. $\mathrm{Cx} 43$ expression was decreased by AngII in a concentrationdependent manner, and this effect was prevented by addition of apelin-13.

Apelin, a peptide released from adipose tissue provides a protective effect in many physiological processes (Sörhede et al. 2005). With direct effects on cardiomyocyte contractility and electrophysiology, apelin is increasingly being regarded as an important regulator of cardiovascular homeostasis (Farkasfalvi et al. 2007). A recent study revealed that the rate of AF was three times higher in patients with low than in those with high apelin levels (Falcone et al. 2010). Thus, apelin may have potential predictive and therapeutic effects on AF. Recent study showed that AngII-mediated cardiac dysfunction, hypertrophy and fibrosis were augmented in apelin knockout mice (Sato et al. 2019). The apelin gene encodes a 77-amino-acid pre-propeptide, which can be cleaved into different bioactive apelin peptides, including apelin-36, apelin-17 and apelin-13, with apelin-13 being predominant in the heart (Chaves et al. 2015). Increased expression of $\mathrm{Cx} 43$ induced by apelin has been found in both mouse and human cardiac embryonic stem cells (Wang et al. 2017). However, it remains unclear whether apelin-13 can prevent the atrial $\mathrm{Cx} 43$ remodeling induced by AngII. We treated HL-1 cells with different concentrations of apelin-13 alone, Western blot analysis showed that the change of $\mathrm{Cx} 43$ expression was not obvious. But treated with apelin-13 and AngII together, apelin-13 significantly increased the downregulation of Cx43 expression induced by AngII.

Ye et al. (2015) demonstrated that overexpression of apelin abolished the cardiac hypertrophy induced by AngII in cultured cardiomyocytes A recent study indicated that in AF patients, cardiac production and the circulating level of BNP were increased, and chronic BNP therapy prevented atrial electrical remodeling in both rabbits with rapid atrial pacing and HL-1 cells with rapid field stimulation (Zhao et al. 2019). However, the functional significance of BNP in HL-1 cell remodeling remains to be determined. Accordingly, cell immunofluorescence using FITC-phalloidin was performed to visualize the cytoskeleton of HL-1 cells to determine cell size. We measured the BNP level and performed fluorescence staining in HL-1 cells and found that apelin-13 could decrease the expression of BNP and cell hypertrophy induced by AngII, and that autophagy may play an important role.

Studies have shown that autophagy has different effects in different situations, having either a pro-survival 
or pro-death effect (Azad et al. 2008). A recent study showed that suppression of autophagy may be a promising target in atrial fibrosis and AF (Lin et al. 2020). Studies have indicated that $C x 43$ remodeling is one of the most important processes in atrial remodeling and is also likely to be associated with autophagy, but the mechanism requires further study. Thus, we attempted to identify the mechanism linking $\mathrm{Cx} 43$, autophagy and hypertrophy.

Although numerous studies have demonstrated that AMPK-related signaling pathways are involved in AngII-induced inflammation in HL-1 cells (Kim et al. 2017), little is known about AngII-induced Cx43 remodeling in HL-1 cells. Our results confirmed that apelin-13 increased AMPK expression, and that compound $\mathrm{C}$ reverses this effect. $\mathrm{AMPK} / \mathrm{mTOR}$ is a major pathway regulating autophagy, thereby affecting cell survival and death. The protective effect of apelin-13 on $\mathrm{Cx} 43$ remodeling induced by high glucose was shown to be dependent on the AMPK/mTOR pathway. The AMPK pathway affects $\mathrm{Cx} 43$ remodeling, but its effect on AngII-induced Cx43 remodeling in HL-1 cells has not been investigated. In our study, compound C (AMPK inhi-bitor) and rapamycin (mTOR inhibitor) were co-treated with apelin-13 to determine whether apelin-13 has a protective or inhibitory effect on AngII-induced Cx43 expression and cell hypertrophy. Our results indicated that apelin-13 has a protective effect on $\mathrm{Cx} 43$ expression, cell hypertrophy and autophagy development. Compound $\mathrm{C}$ inhibits AMPK activity and the protective role of apelin-13 in $\mathrm{Cx} 43$ expression. To evaluate autophagic flux, we used LC3II, which plays a critical role in macroautophagy and is considered a suitable marker of autophagy. LC3II expression was inhibited by compound C, suggesting that AMPK pathway is involved in autophagy activation. However, rapamycin, which inhibits mTOR activity, stimulated autophagy and increased LC3II expression, which could further inhibit Cx43 and AMPK expression and promote cell hypertrophy. These results suggest that increased autophagy has decreasing $\mathrm{Cx} 43$ expression and promotes cell hypertrophy. These results suggest that increased autophagy has decreasing $\mathrm{Cx} 43$ expression and promotes cell hypertrophy (Fig. 5).

\section{HL-1}

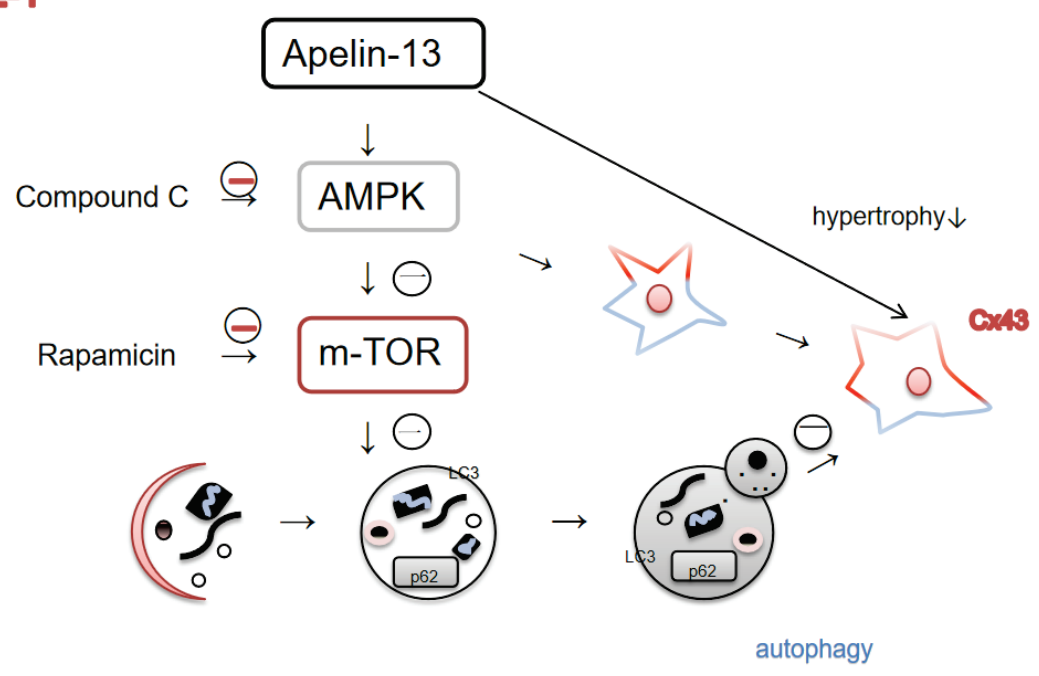

Fig. 5. Functional pathway diagram. Schematic representation showing that apelin-13 increased autophagy and Cx43 expression through an AMPK/mTOR signaling pathway but decreased cell hypertrophy in HL-1 cells. In addition, increased autophagy decreased the expression of $\mathrm{Cx} 43$ and promoted cell hypertrophy.

\section{Conclusions}

AngII decreased Cx43 expression and distribution, stimulated autophagic flux and increased the hypertrophy of HL-1 cells. However, apelin-13 via AMPK/mTOR pathway reversed the AngII-induced effects on Cx43 downregulation and cell hypertrophy in HL-1 cells and further increased autophagy, which in turn inhibited $\mathrm{Cx} 43$ expression and promoted cell hypertrophy. Thus, it's promising that apelin-13 may be a potential agent in prevention or treatment of $\mathrm{AF}$ in the future.

\section{Conflict of Interest}

There is no conflict of interest.

\section{Acknowledgements}

This work was supported by a grant from innovation project of postgraduate education in Shanxi Province (No. 2C592019086). 


\section{References}

AZAD MB, CHEN Y, HENSON ES, CIZEAU J, MCMILLAN-WARD E, ISRAELS SJ, GIBSON SB: Hypoxia induces autophagic cell death in apoptosis-competent cells through a mechanism involving BNIP3. Autophagy 4: 195-204, 2008. https://doi.org/10.4161/auto.5278

CHAVES-ALMAGRO C, CASTAN-LAURELL I, DRAY C, KNAUF C,VALET P, MASRI B: Apelin receptors: From signaling to antidiabetic strategy. Eur J Pharmacol 763: 149-159: 2015. https://doi.org/10.1016/j.ejphar.2015.05.017

CHUGH SS, HAVMOELLER R, NARAYANAN K, SINGH D, RIENSTRA M, BENJAMIN E, GILLUM RF, KIM Y-H, MCANUlTY JH, ZHENG Z-J, FOROUZANFAR MH, NAGHAVI M, MENSAH G, EZZATI M, MURRAY CJL: Worldwide epidemiology of atrial fibrillation: a Global Burden of Disease 2010 Study. Circulation 129: 837-847, 2014. https://doi.org/10.1161/CIRCULATIONAHA.113.005119

FALCONE C, BUZZI MP, D'ANGELO A, SCHIRINZI S, FALCONE R, RORDORF R, CAPETTINI AC, LANDOLINA M, STORTI C, PELISSERO G: Apelin plasma levels predict arrhythmia recurrence in patients with persistent atrial fibrillation. Int J Immunopathol Pharmacol 23: 917-925, 2010. https://doi.org/10.1177/039463201002300328

FARKASFALVI K, STAGG MA, COPPEN SR, SIEDLECKA U, LEE J, SOPPA GK, MARCZIN N, SZOKODI I, YACOUB MH, TERRACCIANO CMN: Direct effects of apelin on cardiomyocyte contractility and electrophysiology. Biochem Biophys Res Commun 357: 889-895, 2007. https://doi.org/10.1016/j.bbrc.2007.04.017

HEIJMAN J, DOBREV D: Irregular rhythm and atrial metabolism are key for the evolution of proarrhythmicatrial remodeling in atrial fibrillation. Basic Res Cardiol 110: 41, 2015. https://doi.org/10.1007/s00395-015-0498-1

KIM N, JUNG Y, NAM M, SUN KANG M, KYUNG LEE M, CHO Y, CHOI E-K, HWANG G-S, SOO KIM H: Angiotensin II affects inflammation mechanisms via AMPK-related signalling pathways in HL-1 atrial myocytes. Sci Rep 7: 10328, 2017. https://doi.org/10.1038/s41598-017-09675-3

LESUR O: Myocardial impact and cardioprotective effects ofapelin-13 and a c-terminal-modified analog during lps and clp experimental sepsis. Intensive Care Med Exp 3 (Suppl 1): A436, 2015. https://doi.org/10.1186/2197-425X-3S1-A436

LEVINE B, KLIONSKY DJ: Development by self-digestion: molecular mechanisms and biological functions of autophagy. Dev Cell 6: 463-477, 2004. https://doi.org/10.1016/S1534-5807(04)00099-1

LEYBAERT L, LAMPE PD, DHEIN S, KWAK BR, FERDINANDY P, BEYER EC, LAIRD DW, NAUS CC, GREEN CR, SCHULZ R: Connexins in cardiovascular and neurovascular health and disease: Pharmacological implications. Pharmacol Rev 69: 396-478, 2017. https://doi.org/10.1124/pr.115.012062

LI A, ROY S: High glucose-induced downregulation of connexin 43 expression promotes apoptosis in microvascular endothelial cells. Invest Ophthalmol Vis Sci 50: 1400-1407, 2009. https://doi.org/10.1167/iovs.07-1519

LI J, WANG S, BAI J, YANG X-L, ZHANG Y-L, CHE Y-L, LI H-H, YANG Y-Z: Novel role for the immunoproteasome subunit PSMB10 in angiotensin II-induced atrial fibrillation in mice. Hypertension 71: 866-876, 2018. https://doi.org/10.1161/HYPERTENSIONAHA.117.10390

LI X, YU L, GAO J, BI X, ZHANG J, XU S, WANG M, CHEN M, QIU F, FU G: Apelin ameliorates high glucoseinduced downregulation of Connexin 43 via AMPK-dependent pathway in neonatal rat cardiomyocytes. Aging Dis 9: 66-76, 2018. https://doi.org/10.16992/ASOS.13996

LIN G, LU HH, SHEN Y, HUANG JF, SHI LS, GUO YN: Meta-analysis of the therapeutic effects of various methods for the treatment of chronic atrial fibrillation. Exp Ther Med 6: 489-496, 2013. https://doi.org/10.3892/etm.2013.1158

LIN R, WU S, ZHU D, QIN M, LIU X: Osteopontin induces atrial fibrosis by activating AKT/GSK-3 $/ / \beta$-catenin pathway and suppressing autophagy. Life Sci 245: 117328, 2020. https://doi.org/10.1016/j.lfs.2020.117328

MITEVA K, VAN LINTHOUT S, PAPPRITZ K, MÜLLER I, SPILLMANN F, HAAG M, STACHELSCHEID H, RINGE J, SITTINGER M, TSCHÖPE C: Human endomyocardial biopsy specimen-derived stromal cells modulate angiotensin II-induced cardiac remodeling. Stem Cells Transl Med 5: 1707-1718, 2016. https://doi.org/10.5966/sctm.2016-0031 
NAGIBIN V, EGAN BENOVA T, VICZENCZOVA C, SZEIFFOVA BACOVA B, DOVINOVA I, BARANCIK M, TRIBULOVA N: Ageing related down-regulation of myocardial connexin-43 and up-regulation of MMP-2 may predict propensity to atrial fibrillation in experimental animals. Physiol Res 65: 91-100, 2016. https://doi.org/10.33549/physiolres.933389

ROCKEL JS, KAPOOR M: Autophagy: controlling cell fate in rheumatic diseases. Nat Rev Rheumatol 13: 193, 2017. https://doi.org/10.1038/nrrheum.2017.17

SATO T, KADOWAKI A, SUZUKI T, ITO H, WATANABE H, IMAI Y, KUBA K: Loss of apelin augments angiotensin II-induced cardiac dysfunction and pathological remodeling. Int J Mol Sci 20: 239, 2019. https://doi.org/10.3390/ijms20020239

SHINOHARA D, MATSUSHITA S, YAMAMOTO T, INABA H, KUWAKI K, SHIMADA A, AMANO A: Reduction of c-kit positive cardiac stem cells in patients with atrial fibrillation. J Cardiol 69: 712-718, 2017. https://doi.org/10.1016/j.jjcc.2016.07.006

SÖRHEDE WM, MAGNUSSON C, AHRÉN B: The apj receptor is expressed in pancreatic islets and its ligand, apelin, inhibits insulin secretion in mice. Regul Pept 131: 12-17, 2005. https://doi.org/10.1016/j.regpep.2005.05.004

TANG H, LI J, LIU X, WANG G, LUO M, DENG H: Down-regulation of HSP60 suppresses the proliferation of glioblastoma cells via the ROS/AMPK/mTOR pathway. Sci Rep 6: 28388, 2016. https://doi.org/10.1038/srep28388

TATEMOTO K, HOSOYA M, HABATA Y, FUJII R, KAKEGAWA T, ZOU MX, KAWAMATA Y, FUKUSUMI S, HINUMA S, KITADA C, KUROKAWA T, ONDA H, FUJINO M: Isolation and characterization of a novel endogenous peptide ligand for the human APJ receptor. Biochem Biophys Res Commun 251: 471-476, 1998. https://doi.org/10.1006/bbrc.1998.9489

TSAI CT, LAI LP, HWANG JJ, CHIANG FT, TSENG CD, LIN JL: Renin-angiotensin system component expression in the HL-1 atrial cell line and in a pig model of atrial fibrillation. J Hypertens 26: 570-582: 2008. https://doi.org/10.1097/HJH.0b013e3282f34a4a

VALLS-LACALLE L, NEGRE-PUJOL C, RODRÍGUEZ C, VARONA S, VALERA-CAÑELLAS A, CONSEGAL M, MARTÍNEZ-GONZÁLEZ J, RODRÍGUEZ-SINOVAS A: Opposite effects of moderate and extreme CX43 deficiency in conditional CX43-deficient mice on angiotensin II-induced cardiac fibrosis. Cells 8: 1299, 2019. https://doi.org/10.3390/cells8101299

WANG IN, WANG X, GE X, ANDERSON J, HO M, ASHLEY E: Apelin enhances directed cardiac differentiation of mouse and human embryonic stem cells. PLoS One 7: e38328, 2017. https://doi.org/10.1371/journal.pone.0038328

XIAO Y, CAI X, ATKINSON A, LOGANTHA SJ, BOYETT M, DOBRZYNSKI H: Expression of connexin 43, ion channels and $\mathrm{Ca} 2+-$ handling proteins in rat pulmonary vein cardiomyocytes. Exp Ther Med 12: 3233-3241, 2016. https://doi.org/10.3892/etm.2016.3766

YANG X, ZHU W, ZHANG P, CHEN K, ZHAO L, LI J, WEI M, LIU M: Apelin-13 stimulates angiogenesis by promoting cross-talk between AMP-activated protein kinase and Akt signaling in myocardial microvascular endothelial cells. Mol Med Rep 9: 1590-1596, 2014. https://doi.org/10.3892/mmr.2014.1984

YE L, DING F, ZHANG L, SHEN A, YAO H, DENG L, DING Y: Serum apelin is associated with left ventricular hypertrophy in untreated hypertension patients: J Transl Med 13: 290, 2015. https://doi.org/10.1186/s12967$\underline{015-0635-5}$

ZHAO H, LI T, LIU G, ZHANG L, LI G, YU J, LOU Q, HE R, ZHAN C, LI L, YANG W, ZANG Y, CHENG C, LI W: Chronic B-Type natriuretic peptide therapy prevents atrial electrical remodeling in a rabbit model of atrial fibrillation. J Cardiovasc Pharmacol Ther 24: 575-585, 2019. https://doi.org/10.1177/1074248419854749 